\title{
Percent Change From Nadir in Sum of Diameter
}

National Cancer Institute

\section{Source}

National Cancer Institute. Percent Change From Nadir in Sum of Diameter. NCI

Thesaurus. Code C112373.

The most recently recorded sum of diameters minus the lowest sum of diameters previously recorded divided by the lowest sum of diameters previously recorded, multiplied by 100 . 